\title{
Forecasting Innovative Development of a Company in the Process of Transformation
}

\author{
Olga Shvaika*, and Marina Kupriyanova \\ Ryazan State Radio Engineering University, Gagarin Str., 59/1, 390005 Ryazan, Russia
}

\begin{abstract}
Innovation is traditionally considered to be an effective instrument of development for industrial enterprises, even at the time of crisis. However, as practical observations show, non-systematic and inconsistence innovative changes may lead to poor results. The sustainable innovative growth is gained as a result of in-depth transformation of all the system elements. The purpose of the research is to formulate an approach to evaluating the expected effect of transformation and restructuring an industrial company and to forecast the perspectives of innovative development. The methodological basis for the research refers to the ideas of the fuzzy set theory and the axiomatic methods of analysis. The axiomatic method makes it possible to construct formalized descriptions of a company and to achieve a sufficient level of detachment. Such descriptions, or texts, may be interpreted by managers as concise information for decision-making. The results of the research find a practical application as tools of evaluating the expected effect of innovation and transformation.
\end{abstract}

\section{Introduction}

Industrial enterprises meet new challenges in the turbulent environment and face the necessity of introducing innovations in the key structural elements [1-5]. These elements include function distribution, financial and economic policies, corporate culture, and technology. Being an innovative enterprise means having effective policies of organization transformation and restructuring in order to solve such problems as (1) improving the operation and production structure and processes, using effective tools of control; (2) forming efficient organization structures and methods of adaptation to the changing market demands; (3) introducing of new production technologies; and (4) working out appropriate principles of corporate culture [6]. The process of transformation and restructuring may be defined as a system of measures that align the enterprise operations and processes with the market demand and the adopted development program [7].

\footnotetext{
* Corresponding author: semer-ka@yandex.ru
} 


\section{Materials and Methods}

The research relies on the methodology of the fuzzy set theory and the axiomatic approach [8-10]. The idea is to formulate a description of an enterprise structure including the interrelated elements and to evaluate the possibility of effective transformation and restructuring process. Transformation and restructuring as one of the instruments of crisis management may take place in different ways. The limitation of the research is that transformation s viewed as a process leading to innovative (and efficient) development of an industrial enterprise. The axiomatic approach makes it possible to differentiate the characteristics of complex mathematical objects and to form membership functions in particular semantic fields. In other words, the approach provides a classification of attributes according to the criteria of their reference to the described structures. As a result, the objects may be analyzed from various perspectives in terms of well-known algebraic, topological and mathematical notions [11].

Let $\mathrm{x}, \mathrm{y}, \mathrm{z}, \ldots$ be elements of the enterprise that is intended for transformation and innovative development. In general, there might exist a set $X$ of such elements, so that $x, y$, $z \in X$. An enterprise is a complex structure of interrelated elements [7]. To produce a limited nomenclature of products an enterprise needs such inputs as technology, equipment, and qualified labor resources. The simplified model of elements is based on well-know inputoutput models [12]. The notion of innovative development may be represented as a binary relation of $\mathrm{R}$ between the elements $\mathrm{x}, \mathrm{y}, \mathrm{z} \in \mathrm{X}$. There may be formulated several properties of this relation. Any element of innovative development is self-equivalent, i.e. $x R x, y R y$, $z R z$. Therefore, the reflexive property may be applied to the elements $x, y, z \in X$.

If element $x$ is equivalent to element $y$, i.e. $x$ R, and $y$ is equivalent to $x$, i.e. $y R x$, then this property of the elements point out at the symmetry of the elements $\mathrm{x}$ and $\mathrm{y}$. This makes it possible to switch from one element to another. In other words, there is no difference which of the elements is analyzed first.

If element $\mathrm{x}$ is equivalent to element $\mathrm{y}$, i.e. $\mathrm{xRy}$ and $\mathrm{y}$ is equivalent to $\mathrm{z}$, i.e. $\mathrm{yRz}$, then $\mathrm{x}$ is equivalent to $z$, i.e. $x R z$. Therefore, the property of transitivity may be applied to the elements of the transformation and restructuring process. According to the fuzzy set theory, the proposed concept of innovative development as a binary relation $\mathrm{R}$ is an equivalence relation. The introduced relation $\mathrm{R}$ of innovative development makes it possible to split the set $\mathrm{X}$ into classes of equivalency, or a co-set of classes $\{\mathrm{X}\}_{\mathrm{R}}$. Five co-set classes are further distinguished: $\left\{\mathrm{x}_{\mathrm{K}}\right\}_{\mathrm{R}}-$ personnel; $\left\{\mathrm{x}_{\mathrm{T}}\right\}_{\mathrm{R}}-$ technology; $\left\{\mathrm{x}_{\mathrm{O}}\right\}_{\mathrm{R}}$ - equipment; $\left\{\mathrm{x}_{\Pi}\right\}_{\mathrm{R}}$ product; $\left\{\mathrm{x}_{\mathrm{c}, \mathrm{M}}\right\}_{\mathrm{R}}$ - raw material. The introduced co-set classes have the following properties:

a. any of the classes is nonempty due to the reflexivity $\mathrm{R}$

b. the equality of co-set classes $\left\{x^{\prime}\right\}_{R}=\left\{x^{\prime \prime}\right\}_{R}$ is equivalent to $x^{\prime} R x^{\prime \prime}$;

c. two co-set classes either coincide, or are disjoint:

$$
\begin{gathered}
x^{\prime} R x^{\prime} \leftrightarrow\left\{x^{\prime}\right\}_{R}=\left\{x^{\prime}\right\}_{R}, \\
x^{\prime} R x \leftrightarrow\left\{x^{\prime}\right\}_{R} \cap\left\{x^{\prime}\right\}_{R}=\varnothing ;
\end{gathered}
$$

d. a merge of co-set classes is equal to $\mathrm{X}$ :

$$
\cap\{\mathrm{X}\} \mathrm{R}=\mathrm{X}
$$

This implies that a multitude of co-set classes represents a split of $\mathrm{X}$, and each co-set class $\{\mathrm{X}\}_{\mathrm{R}}$ serves as a block of this split. The opposite statement is true: each split of $\mathrm{X}$ corresponds to certain relation of equivalency $\mathrm{R}$, and the co-set classes are the split blocks. 
Furthermore, a set with elements being co-set classes with the relation of equivalence $\mathrm{R}$, is a factor multitude $X / R$ of $X$ set by $R$. The notion $X \rightarrow X / R$ is such that every $x \in X$ corresponding to a certain co-set class to which this $\mathrm{X}$ belongs. This notion is a factor representation $\mathrm{X}$ in $\mathrm{X} / \mathrm{R}$.

The new sets $\left\{\mathrm{X}_{\mathrm{K}}\right\}_{\mathrm{R}}$ - personnel; $\left\{\mathrm{X}_{\mathrm{T}}\right\}_{\mathrm{R}}$ - technology; $\left\{\mathrm{x}_{\mathrm{O}}\right\}_{\mathrm{R}}$ - equipment; $\left\{\mathrm{x}_{\Pi}\right\}_{\mathrm{R}}$ - product; $\left\{\mathrm{x}_{\mathrm{c}, \mathrm{M}}\right\}_{\mathrm{R}}$ - raw material are supplementary. Together with the main sets they form a scale of $\mathrm{M}$ sets. It means that in pairs they may be subject to any mathematical operations, which result in additional supplementary sets. Definition of a unique element from a scale set is the result of defining a certain number of elements of the scale set, formulating the relations between common elements of these sets, reflecting some subsets of these sets into other ones.

\section{Results and Discussion}

The results of applying the axiomatic approach to the process of transformation and restructuring an enterprise are forecasts of innovative development for each of the defined elements. Several scales are formulated to evaluate the innovative efficiency. The choice of variants is realized by the criterion of operational complexity in each element. If the state of an element does not correspond to the target, it is necessary to take measures for improving it. The choice criteria may be the following:

a. time needed for introducing changes to a particular element

b. cost of changes, acceptable for the enterprise

c. subjective factors influencing the decision makers, their personal likes and dislikes

d. results of innovation, the depth of qualitative transformation allowing to make a considerable shift in performance.

To give an example, it is possible to apply the method to the Personnel element of an enterprise.

Human factor makes this element the most important and the most complicated one among others. An innovative enterprise has three key categories of personnel: (1) administrative, (2) R\&D, (3) main and support staff. The R\&D personnel is included in case the enterprise is engaged in the sphere of scientific research and development. The R\&D personnel may either generate, or implement innovations. This type of operations demand highly qualified specialists. A concept of innovative human resources (HR) policy is introduced as a binary relation R1 between the elements of the equivalence class $\left\{\mathrm{X}_{\mathrm{K}}\right\}_{\mathrm{R}}-$ personnel, i.e. $\mathrm{x}_{\mathrm{K}}, \mathrm{y}_{\mathrm{K}}, \mathrm{z}_{\mathrm{K}} \in\left\{\mathrm{x}_{\mathrm{K}}\right\}_{\mathrm{R}}$. Let's consider the particular properties of the introduced relation. Any element of the HR policy is self equivalent, i.e. $x_{K} R 1 x_{K}, y_{K} R 1 y_{K}, z_{K} R 1 z_{K}$. Therefore, this implies that there is a condition of reflexivity of the elements:

$$
\mathrm{X}_{\mathrm{K}}, \mathrm{y}_{\mathrm{K}}, \mathrm{z}_{\mathrm{K}} \in\left\{\mathrm{x}_{\mathrm{K}}\right\}_{\mathrm{R}}
$$

If element $x_{K}$ is equivalent to element $y_{K}$, i.e. $x_{K} R 1 y_{K}$, and $y$ is equivalent to $x_{K}$, i.e. $y_{K} R 1 x_{K}$, then this attribute of the class of equivalence $\left\{x_{K}\right\}_{R}$ indicates that fuzzy elements $x_{K}$ and $\mathrm{y}_{\kappa}$, have the attribute of symmetry. It makes it possible to switch from one element to another. In other words, the order of analysis is not significant. Furthermore, if element $\mathrm{x}_{\mathrm{K}}$ is equivalent to element $y_{\kappa}$, i.e. $x_{K} R 1 y_{K}$ and $y_{K}$ is equivalent to element $z_{K}$, i.e. $y_{K} R 1 z_{K}$, then it is possible to define that $x_{K}$ is equivalent to element $z_{K}$, i.e. $x_{K} R 1 z_{K}$.

Therefore, the property of transitivity may be applied to the elements of the class of equivalence $\left\{\mathrm{X}_{\mathrm{K}}\right\}_{\mathrm{R}}$. Then, according to the fuzzy set theory, the introduced notion of HR policy as a binary relation $\mathrm{R} 1$ is an equivalence relation [12]. The introduced relation $\mathrm{R} 1$ of 
innovative HR policy makes it possible to split the class of equivalence $\left\{\mathrm{x}_{\mathrm{K}}\right\}_{\mathrm{R}}$ - personnel into subclasses of equivalence, as a conjunction of co-set of classes $\{\mathrm{X}\} \mathrm{R}$.

Four co-set classes are further distinguished: $\left\{\left\{\mathrm{x}_{0 \sigma}\right\}_{\mathrm{R} 1}\right\}$ - education; $\left\{\left\{\mathrm{x}_{\mathrm{KB}}\right\}_{\mathrm{R}}\right\}$ qualification; $\left\{\left\{\mathrm{X}_{\mathrm{Bи}}\right\}_{\mathrm{R}}\right\}-$ readiness for innovation; $\left\{\left\{\mathrm{X}_{\mathrm{cк}}\right\}_{\mathrm{R}}\right\}$ - social compatibility. Depending on the specific features of a particular enterprise, the list of co-set classes may be completed and improved. Thus, according to theses subclasses, there may be differentiated several variants of development for this element (Fig. 1).

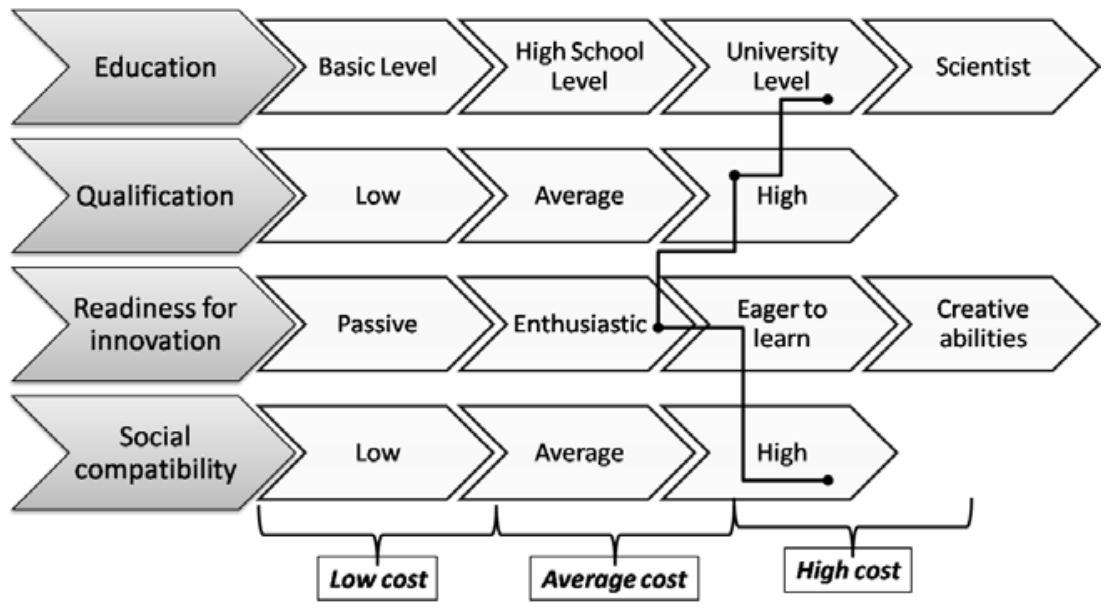

Fig. 1. A scale of evaluating the potential for innovative development, the Personnel element.

The introduced subclasses $\left\{\left\{\mathrm{X}_{\mathrm{K}}\right\}_{\mathrm{R} 1}\right\}$ have the same properties as the classes of equivalence $\left\{\mathrm{X}_{\mathrm{K}}\right\}_{\mathrm{R}}$.

Thus the key influencing elements of the innovative HR policy may refer to the following fuzzy sets:

a. the level of education

b. qualification

c. readiness for innovation: this criterion is important for the administrative personnel, the tempo of innovative development is to a large extent dependent on the appetite for innovation among decision-makers

d. social compatibility: as practical observations show, team workers are rarely excellent in creative abilities, but they are the drivers of successful and sustainable development

The next step is evaluation of every particular worker according to these criteria and taking into account the functional scope and complexity of the role in the enterprise.

For example, a top-manager is expected to have such attributes as university level of education, a high level of qualification, a high level of social compatibility, a good level of readiness for innovation. For an R\&D staff member it is not so vital to have high compatibility with the team. What is expected from them is a sufficient level of creativity and an enthusiastic attitude to innovation.

The main staff members need to have an appropriate level of education, sufficient for their task performance. Average social compatibility and ability to learn are important characteristics. The lower the requirements, the lower the cost for human resources is. At the same time, most experts state that innovation proves to be effective only if the human resources are of high quality. The comparison of every staff member follows a certain pattern (Fig. 2). 


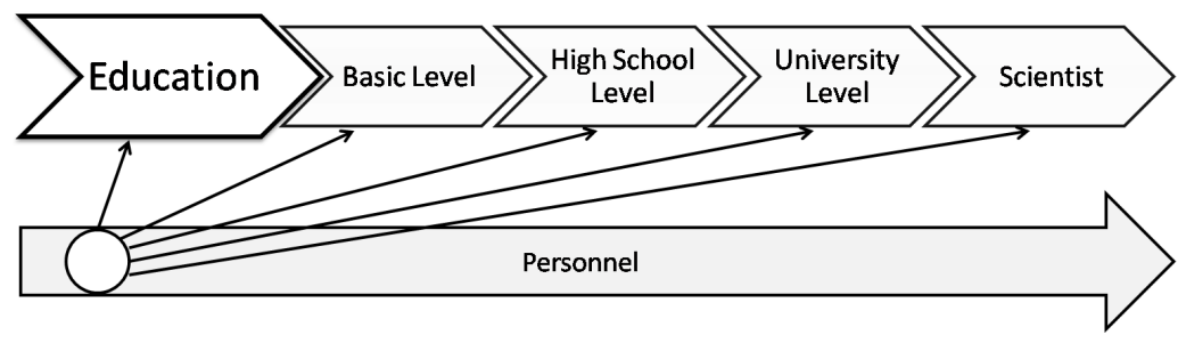

Fig. 2. Variants of comparison.

If a staff member has a high school level of education and if it meets the requirements, it means that the target level of education for this particular job position is equal or higher than the level of high school. In this case the company will develop efficiently. Depending on the requirements, the target level shifts from lower to higher until the minimum sufficient level is chosen.

The higher the level of education, the more results are expected to be gained from the human resources. However, high qualification and work experience may compensate for the lack of proper education. The procedure of appointment for a particular position is different for new personnel and for the already working staff members. If the enterprise chooses a new strategy of development, it does not necessarily mean recruitment of new specialists. There can be introduced innovative measures of human resource management in order to support qualification growth of the already working staff.

Transformation and restructuring the Personnel element of a company is realized via such measures as improvement of requirements to recruitment, organization of educational programs for the specialists who need to acquire new competencies, exchange of successful practices with other enterprises, salary growth and bonuses, support of scientific research and personal development, career management, changes in the administrative system and distribution of rights and obligations, decentralization of authority, etc. Fig. 3 illustrates the equivalence scale according to the criteria of the life cycle.

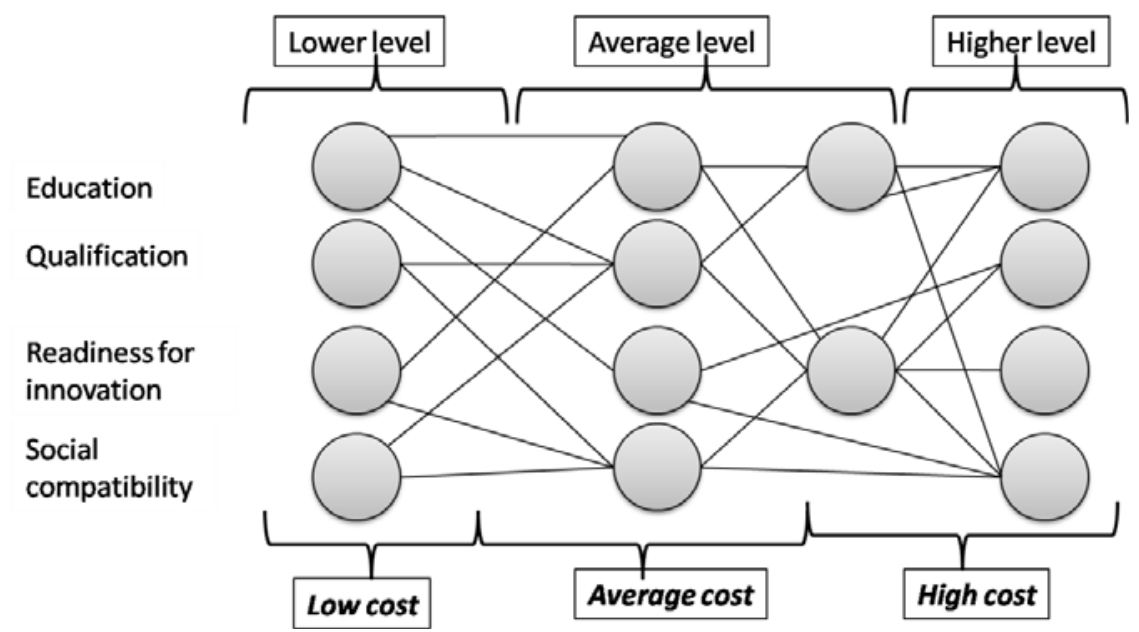

Fig. 3. The equivalence scale for the Personnel element

The other elements of an enterprise may have numerous subsets of properties (Table 1). 
Table 1. Subsets of properties for the five key elements of analysis.

\begin{tabular}{|c|c|c|c|c|}
\hline $\begin{array}{c}\left.\mathrm{X}_{\mathrm{K}}\right\}_{\mathrm{R}}- \\
\text { personnel }\end{array}$ & $\begin{array}{c}\left\{x_{T_{1}}\right\}_{\mathrm{R}}- \\
\text { technology }\end{array}$ & $\begin{array}{c}\left\{x_{0}\right\}_{R}- \\
\text { equipment }\end{array}$ & $\begin{array}{l}\left.\mathbf{x}_{\mathrm{n}}\right\}_{\mathrm{R}}- \\
\text { product }\end{array}$ & $\begin{array}{c}\left.\mathbf{x}_{\mathrm{c}, \mathrm{M}}\right\}_{\mathrm{R}}- \\
\text { raw } \\
\text { material }\end{array}$ \\
\hline $\begin{array}{l}\{\{\mathrm{xo \sigma}\} \mathrm{R} 1\} \\
\text { education }\end{array}$ & $\begin{array}{l}\left\{\left\{\mathrm{x}_{\mathrm{c} \sigma}\right\} \mathrm{R} 2\right\} \text { way of } \\
\text { implementation }\end{array}$ & $\begin{array}{l}\left\{\left\{\mathrm{x}_{\mathrm{cn}}\right\} \mathrm{R} 3\right\} \text { way of } \\
\text { implementation }\end{array}$ & $\begin{array}{c}\left\{\left\{\mathrm{X}_{\mathrm{pH}}\right\} \mathrm{R} 4\right\} \\
\text { novelty for th } \\
\text { market }\end{array}$ & $\begin{array}{c}\left.\left\{\left\{\mathrm{X}_{\mathrm{K}}\right\}\right\}_{\mathrm{R} 5}\right\} \\
\text { quality }\end{array}$ \\
\hline $\begin{array}{c}\{\{\mathrm{x \kappa в}\} \mathrm{R} 1\} \\
\text { qualification }\end{array}$ & $\begin{array}{c}\left\{\left\{\mathrm{Xxc}_{\mathrm{yc}}\right\} \mathrm{R} 2\right\} \text { level of } \\
\text { complexity }\end{array}$ & $\begin{array}{c}\left\{\left\{\mathrm{X}_{\text {из }}\right\} \text { R } 3\right\} \\
\text { depreciation }\end{array}$ & $\begin{array}{c}\quad\left\{\left\{\mathrm{X}_{\mathrm{Hn}}\right\} \mathrm{R} 4\right\} \\
\text { novelty for } \\
\text { the enterprise }\end{array}$ & $\begin{array}{c}\left\{\left\{\mathrm{X}_{\mathrm{C} 3}\right\} \mathrm{R} 5\right\} \\
\text { cost of } \\
\text { purchase }\end{array}$ \\
\hline $\begin{array}{c}\left\{\left\{\mathrm{X}_{\mathrm{Bn}}\right\}_{\mathrm{R} 1}\right\} \\
\text { readiness for } \\
\text { innovation }\end{array}$ & $\begin{array}{c}\left\{\left\{\mathrm{X}_{\mathrm{p}}\right\} \mathrm{R} 2\right\} \text { resource } \\
\text { intensity }\end{array}$ & $\begin{array}{c}\left\{\left\{\mathrm{X}_{\mathrm{yc}}\right\}_{\mathrm{R} 3}\right\} \text { level of } \\
\text { complexity }\end{array}$ & $\left\{\left\{\mathrm{x}_{\mathrm{cc}}\right\} \mathrm{R} 4\right\} \cos \mathrm{t}$ & $\begin{array}{c}\left\{\left\{\mathrm{X}_{\mathrm{H \Pi}}\right\} \mathrm{R} 5\right\} \\
\text { suppliers } \\
\text { stability }\end{array}$ \\
\hline \multirow[t]{2}{*}{$\begin{array}{c}\left\{\left\{\mathrm{X}_{\mathrm{ck}}\right\} \mathrm{R} 1\right\} \text { social } \\
\text { compatibility }\end{array}$} & $\begin{array}{l}\left\{\left\{\mathrm{x}_{9}\right\}_{\mathrm{R} 2}\right\} \text { energy } \\
\text { intensity }\end{array}$ & $\begin{array}{c}\left\{\left\{\mathrm{x}_{\text {пp }}\right\} \mathrm{R} 3\right\} \\
\text { productivity }\end{array}$ & $\begin{array}{c}\left\{\left\{\mathrm{X}_{\mathrm{p} n}\right\} \mathrm{R} 5\right\} \\
\text { sales } \\
\text { rentability }\end{array}$ & $\begin{array}{c}\left\{\left\{\mathrm{X}_{\mathrm{pc} 3}\right\} \mathrm{R} 5\right\} \\
\text { stocks } \\
\text { capacity }\end{array}$ \\
\hline & & $\begin{array}{l}\left\{\left\{\mathrm{X}_{\text {эк }}\right\} \mathrm{R} 3\right\} \\
\text { profitability }\end{array}$ & & \\
\hline
\end{tabular}

These new defined subsets are supplementary. Together with the five key elements $\left\{\mathrm{x}_{\mathrm{K}}\right\}_{\mathrm{R}}-$ personnel; $\left\{\mathrm{x}_{\mathrm{T}}\right\}_{\mathrm{R}}-$ technology; $\left\{\mathrm{x}_{\mathrm{O}}\right\}_{\mathrm{R}}$ - equipment; $\left\{\mathrm{x}_{\mathrm{\Pi}}\right\}_{\mathrm{R}}-$ product; $\left\{\mathrm{x}_{\mathrm{c}, \mathrm{M}}\right\}_{\mathrm{R}}-$ raw material the supplementary subsets for the $\mathrm{M}$ scale of sets. It means that in pairs they may be subject to any mathematical operations. The operations produce additional supplementary subsets. Definition of a unique element from a scale set is the result of defining a certain number of elements of the scale set, formulating the relations between common elements of these sets, reflecting some subsets of these sets into other ones. At the $\mathrm{M}$ scale a particular set of properties is defined as a crispy set of elements belonging to the $\mathrm{M}$ set of properties. Let $\mathrm{S}$ be the conjunction of subsets of the $\mathrm{M}$ set defined by these properties. Then element $\mathrm{s} \in \mathrm{S}$ is defined in the database $\left\{\mathrm{x}_{\mathrm{K}}\right\}_{\mathrm{R}}-$ personnel; $\left\{\mathrm{x}_{\mathrm{T}}\right\}_{\mathrm{R}}-$ technology; $\left\{\mathrm{x}_{\mathrm{O}}\right\}_{\mathrm{R}}$ - equipment; $\left\{\mathrm{x}_{\mathrm{\Pi}}\right\}_{\mathrm{R}}$ - product; $\left\{\mathrm{x}_{\mathrm{c}, \mathrm{M}}\right\}_{\mathrm{R}}$ - raw material and $\mathrm{X}$ structure $\mathrm{S}$ type which is characterized by the $\mathrm{M}$ scale of formation and the properties defined by S. Axiom introduction into the type structure is the final stage of defining the core of the axiomatic theory. It is similar to a gen in which the total information of the theory is preserved in a compressed mode. In concept construction axioms play the role play the role of mathematic prototypes of programs. The programs may be realized in the form of database systems that control the database integrity in operations with the data sets (input, alternations, and output). Correspondingly, the programs check the total content of the database including every element at the moment it is put in. The programs check the compliance with the requirements formulated in the axioms. Interpretation of letters referred to the structures of $\mathrm{T}$ type is fulfilled in terms of a natural language. This is a linguistic interpretation which defines the names of sets, to which the elements belong. This predetermines either an object, or a fuzzy interpretation. A T type structure corresponds to a lattice with its head comprised of linguistic interpretations of the type structure together with linguistic interpretations of the corresponding projections. The second stage of implementing the method is lattice formation for each element of the enterprise (Table 2).

Table 2. Evaluation criteria for the Personnel element.

\begin{tabular}{|l|l|l|l|}
\hline Subjective choice & $\begin{array}{c}\text { Time span needed for } \\
\text { transformation of the } \\
\text { element (here ranged in } \\
\text { the order of growth) }\end{array}$ & $\begin{array}{c}\text { Innovative result } \\
\text { (for the enterprise) }\end{array}$ \\
\hline
\end{tabular}


Table 2. Continued

\begin{tabular}{|c|c|c|c|}
\hline $\begin{array}{c}\text { This part is } \\
\text { completed } \\
\text { according to } \\
\text { subjective views of } \\
\text { the decision maker }\end{array}$ & $\begin{array}{c}\text { Short educational courses } \\
\text { for specialists }\end{array}$ & $\begin{array}{c}\text { Recruitment of } \\
\text { new specialists } \\
\text { instead of previous } \\
\text { staff members }\end{array}$ & $\begin{array}{c}\text { Experience } \\
\text { exchange with other } \\
\text { enterprises of the } \\
\text { economic sector }\end{array}$ \\
\cline { 2 - 4 } & $\begin{array}{c}\text { University level of } \\
\text { education }\end{array}$ & $\begin{array}{c}\text { Payment for } \\
\text { education of a } \\
\text { specialist }\end{array}$ & $\begin{array}{c}\text { High education as a } \\
\text { requirement for a } \\
\text { particular category } \\
\text { of specialists }\end{array}$ \\
\cline { 2 - 4 } & Science degree & $\begin{array}{c}\text { Salary growth for } \\
\text { high qualification }\end{array}$ & $\begin{array}{c}\text { Corporate culture } \\
\text { improvement }\end{array}$ \\
\hline
\end{tabular}

The final step of the method is completing a table with the variants of innovative development in order to improve each of the elements (table 3 ).

Table 3. Variants of innovation oriented measures for each of the elements.

\begin{tabular}{|c|c|c|c|c|}
\hline $\begin{array}{c}\text { Personnel } \\
\text { requirements to } \\
\text { recruitment }\end{array}$ & $\begin{array}{c}\text { Selling part of old } \\
\text { equipment }\end{array}$ & $\begin{array}{c}\text { Technology } \\
\text { Working out } \\
\text { new } \\
\text { technology }\end{array}$ & $\begin{array}{c}\text { Raw material } \\
\text { Searching for } \\
\text { new suppliers }\end{array}$ & $\begin{array}{c}\text { Production } \\
\text { Corporate culture } \\
\text { product }\end{array}$ \\
\hline $\begin{array}{c}\text { Improvement } \\
\text { the administrative } \\
\text { structure }\end{array}$ & $\begin{array}{c}\text { Buying new } \\
\text { equipment } \\
\text { old }\end{array}$ & $\begin{array}{c}\text { Limiting the } \\
\text { stocks }\end{array}$ & $\begin{array}{c}\text { Introducing } \\
\text { innovation to the } \\
\text { roduction process }\end{array}$ \\
\hline $\begin{array}{c}\text { Change in the } \\
\text { methods of HR } \\
\text { management }\end{array}$ & $\begin{array}{c}\text { Training the } \\
\text { specialists to work } \\
\text { with the new } \\
\text { equipment }\end{array}$ & $\begin{array}{c}\text { Leasing part } \\
\text { of the } \\
\text { warehouse } \\
\text { space }\end{array}$ & $\begin{array}{c}\text { Discontinue the } \\
\text { production of a } \\
\text { product }\end{array}$ \\
\hline
\end{tabular}

The result of the analysis is a list of measures appropriate for each of the elements and a forecast of the expected economic effect. The chosen measures indicate the path of development aligned with the intended strategy of development. Each measure is estimated according to its potential cost and profit.

\section{Conclusions}

The study discusses urgent problems of forecasting innovative development of an enterprise in the process of transformation and restructuring. Special attention is paid to the innovative development of the key elements of an enterprise. The core of the proposed approach is a comprehensive view of an enterprise as an integral unity of elements (here these are the personnel, technology, equipment, product, and raw material). The choice of the elements depends on the specific characteristics of the enterprise. The analysis includes forecasting of development for each of the elements on the basis of criteria at the scales of innovative development and the scales of their coherence with the life cycle parameters with the help of the axiomatic approach. Similarly, the choice of criteria for the scales is formulated individually for a particular enterprise. The approach has been applied to industrial enterprises in order to work out a program of their efficient transformation. 


\section{References}

1. A. Coad, N. Grassano, B. H. Hall, P. Moncada-Paternò-Castello, A. Vezzani, Structural Change and Economic Dynamics, 50, 126 (2019)

2. F. Gault, Res. Policy, 47, 617 (2018)

3. G. Lu, P. Dai, X. Zhang, CPE, 1, 284 (2018)

4. X. Song, Y. Ding, Journal of Intelligent \& Fuzzy Systems, 37, 1649 (2019)

5. M. Žižka, V. H. Valentová, N. Pelloneová, E. Štichhauerová, ESI, 5, 4, 780 (2018)

6. M. D. Aistova, Restructuring of Enterprises (Moscow, Alpina Publisher, 2002)

7. O. B. Kazakova, Opportunities of innovative development (Ufa, Gilem, 2007)

8. L. R. Burra, P. Poosapati, International Journal of Computer Applications, 11, 7 (2016)

9. B. K. Wong, V. S. Lai, International Journal of Production Economics, 129, 157 (2011)

10. O. Kulak, S. Cebi, C. Kahraman, Expert Systems with Applications, 37, 6705 (2010)

11. F. J. Gouillart, J. N. Kelly, Transforming the Organization (1996)

12. A.Y. Bass, Theoretical fundamentals of a permanent investment process (2006) 